\title{
Biodegradation of Poly(Lactic Acid) Biocomposites under Controlled Composting Conditions and Freshwater Biotope
}

\author{
Pavel Brdlík*(D), Martin Borůvka (D), Luboš Běhálek (D) and Petr Lenfeld \\ Faculty of Mechanical Engineering, Technical University of Liberec, Studentska 1402/2, 46117 Liberec, \\ Czech Republic; martin.boruvka@tul.cz (M.B.); lubos.behalek@tul.cz (L.B.); petr.lenfeld@tul.cz (P.L.) \\ * Correspondence: pavel.brdlik@tul.cz; Tel.: +420-485-353-335
}

Citation: Brdlík, P.; Borůvka, M.

Běhálek, L.; Lenfeld, P.

Biodegradation of Poly(Lactic Acid) Biocomposites under Controlled Composting Conditions and Freshwater Biotope. Polymers 2021, 13, 594. https://doi.org/10.3390/ polym13040594

Academic Editor: José Miguel Ferri

Received: 25 January 2021

Accepted: 15 February 2021

Published: 16 February 2021

Publisher's Note: MDPI stays neutral with regard to jurisdictional claims in published maps and institutional affiliations.

Copyright: (c) 2021 by the authors. Licensee MDPI, Basel, Switzerland. This article is an open access article distributed under the terms and conditions of the Creative Commons Attribution (CC BY) license (https:// creativecommons.org/licenses/by/ $4.0 /)$.

\begin{abstract}
The influence of additives such as natural-based plasticiser acetyl tributyl citrate (ATBC), $\mathrm{CaCO}_{3}$ and lignin-coated cellulose nanocrystals (L-CNC) on the biodegradation of polylactic acid (PLA) biocomposites was studied by monitoring microbial metabolic activity through respirometry. Ternary biocomposites and control samples were processed by a twin-screw extruder equipped with a flat film die. Commonly available compost was used for the determination of the ultimate aerobic biodegradability of PLA biocomposites under controlled composting conditions (ISO 14855-1). In addition, the hydro-degradability of prepared films in a freshwater biotope was analysed. To determine the efficiency of hydro-degradation, qualitative analyses (SEM, DSC, TGA and FTIR) were conducted. The results showed obvious differences in the degradation rate of PLA biocomposites. The application of ATBC at $10 \mathrm{wt} . \%$ loading increased the biodegradation rate of PLA. The addition of 10 wt. $\%$ of $\mathrm{CaCO}_{3}$ into the plasticised PLA matrix ensured an even higher degradation rate at aerobic thermophilic composting conditions. In such samples (PLA/ATBC/CaCO 3$), 94 \%$ biodegradation in 60 days was observed. In contrast, neat PLA exposed to the same conditions achieved only $16 \%$ biodegradation. Slightly inhibited microorganism activity was also observed for ternary PLA biocomposites containing L-CNC (1 wt.\% loading). The results of qualitative analyses of degradation in a freshwater biotope confirmed increased biodegradation potential of ternary biocomposites containing both $\mathrm{CaCO}_{3}$ and ATBC. Significant differences in the chemical and structural compositions of PLA biocomposites were found in the evaluated period of three months.
\end{abstract}

Keywords: biocomposites; poly(lactic acid); plasticiser; $\mathrm{CaCO}_{3}$; nano-cellulose; aerobic biodegradation; freshwater biotope

\section{Introduction}

Environmental pollution caused by petroleum-based plastic products is one of the anthropogenic impacts that our planet and its ecosystems face today. Therefore, focusing on the development of biodegradable materials from renewable sources is tremendously important. There are currently several commonly available biopolymers on the market [1,2]. Polylactic acid (PLA), due to its relatively good barrier properties to aromas and high mechanical strength and modulus, is one of the most used biopolymers today [3,4]. Unfortunately, there are also some limits that restrict its applicability, particularly its low thermal resistance and high brittleness. There are several modifications that can be used to treat these limits [5]. In the packing industry, low flexibility and resistance to fracture are very often optimised by the addition of plasticisers [6]. Phthalic acid esters have become the most-commonly used class of plasticisers in the 21st century [7]. However, a problem regarding the migration of phthalates and its negative impact on human health has been presented in several works [6-8]. Consequently, there is increasing interest in the development of new eco-friendly natural-based plasticisers. Various types of plasticisers have already been tested with PLA, such as poly(ethylene glycol) (PEG), citrate esters [9-11], oligomeric lactic acid and triacetin [12]. Other limits, such as the low thermal resistance 
and other mechanical and barrier properties, can be improved through an increase in crystallisation kinetics $[13,14]$. One very effective way to do so is increasing nucleation density by adding a heterogeneous nucleation agent [15]. The synergistic effect of heterogeneous nucleation and increased chain mobility due to the addition of both nucleation agents and plasticisers can positively affect the crystallinity degree of PLA [16].

The degradation of biopolymers is generally assumed to be excellent. However, the degradation rate varies among these materials [17]. The scission of the main and/or side chains of the macromolecules can be initiated by a process such as photolysis, oxidation, radiolysis, thermal activation, hydrolysis or biological activity [18]. For polyesters, the hydrolysis and microbial/enzymatic activity are the most important mechanisms [18]. Therefore, medium characteristics (e.g., temperature, $\mathrm{pH}$, the presence and flow of oxygen) are tremendously important in the biodegradation process. Temperature, in particular, is a crucial factor. When PLA is exposed to higher temperatures than the glass transition temperature, the flexibility of the polymer chain is increased. Consequently, PLA easily facilitates the hydrolysis reaction and the attachment of microbes/enzymes [19]. Itävaara et al. [20] reported on the influence of temperature on aerobic and anaerobic biodegradation processes. Their results showed that higher levels of biodegradation were achieved at higher temperatures. Moreover, Kolstad et al. [21] and Karlssion et al. [22] found significant differences in the biodegradation of PLA exposed to mesophilic and thermophilic conditions. Nevertheless, temperatures higher than thermophilic conditions $\left(45-65{ }^{\circ} \mathrm{C}\right)$ are not desirable as they result in the death of microorganisms. Alkaline conditions during composting may also enhance hydrolysis and, thus, biodegradation [20]. The pH of the medium is another characteristic worthy of consideration. For most microorganisms and enzymes, a pH-neutral medium is optimal. During the biodegradation process, the polymer itself can influence the $\mathrm{pH}$ of the medium. Kale et al. [23] found that the PLA during composting caused production of metabolites, resulting in decreased $\mathrm{pH}$ and, thus, lower levels of microorganism activity. Chemical composition, stereoregular conformation of the lactide group, copolymerisation, blending and properties such as molecular mass, density and crystallinity degree are other major aspects in the PLA biodegradation process. Cadar et al. [24] reported some correlation in the composting and level of biodegradation of PLA-based copolymers. The biodegradation of copolymers containing higher amounts of lactic acid was found to be faster than the biodegradation of copolymers containing smaller amounts. Similar results were reported by Iovino et al. [25] and Soni et al. [26]. Furthermore, Kolstad et al. [21] reported very poor biodegradability with semicrystalline PLA when compared to amorphous PLA. This is because water molecules easily diffuse into amorphous regions, and these regions are also easily assimilated by microorganisms [27]. In the research of Kallel et al. [28], a positive effect on biodegradation behaviour was detected following the blending of PLA with PEG. Furthermore, Samadi et al. [17] reported increased biodegradation following the blending of highly degradable PEG with PLA.

Regarding the previous summary, plenty of studies concerned with the PLA biodegradation process have been published. However, the influence of additives such as plasticisers and heterogeneous nucleation agents has still not been sufficiently explained. Therefore, the current work is dedicated to evaluating the influence of bio-based plasticiser acetyl tributyl citrate (ATBC), spray-dried lignin-coated cellulose nanocrystals (L-CNC) and calcium carbonate $\left(\mathrm{CaCO}_{3}\right)$ on the biodegradation behaviour of PLA. As this behaviour is considerably influenced by the medium's characteristics, two different biodegradation tests were performed. The first was concerned with the determination of the ultimate aerobic biodegradability under controlled composting conditions at $58{ }^{\circ} \mathrm{C}$ (ISO 14855-1), while the second was focused on the analysis of biodegradability in the freshwater biotope $\left(25^{\circ} \mathrm{C}\right)$. 


\section{Materials and Methods}

The commercial PLA under the trade name of Ingeo 3001D was supplied by Nature Works (Minnetonka, MN, USA). It is a material that contains $95 \mathrm{wt}$ \% of L-lactide and has an approximate molecular mass of $155,000 \mathrm{~g} / \mathrm{mol}$, glass transition temperature of $60{ }^{\circ} \mathrm{C}$ and melting point of $170{ }^{\circ} \mathrm{C}$. Furthermore, ATBC under the trade name of Citroflex A-4 (Vertellus Holding LLC, Indianapolis, IN, USA) was used in the form of an oily liquid as a plasticiser. Spray-dried L-CNC (BioPlus- ${ }^{\mathrm{TM}}$ Crystals, Orlando, FA, USA) with an average particle size of 4-5 $\mathrm{nm}$ in width and $500 \mathrm{~nm}$ in length were purchased from American Process Inc. (Atlanta, GA, USA) and used as a nucleation agent. Precipitated calcium carbonate $\left(\mathrm{CaCO}_{3}\right)$ (Honeywell Fluka, Seelze, Germany) with an average particle size lower than $1 \mu \mathrm{m}$ was also used as a nucleation agent.

\subsection{Preparation of PLA Films}

The PLA pellets, as well as the $\mathrm{L}-\mathrm{CNC}$ and $\mathrm{CaCO}_{3}$ nucleation additives, were dried for $24 \mathrm{~h}$ at $50{ }^{\circ} \mathrm{C}$ in vacuum oven VD53 (Binder $\mathrm{GmbH}$, Tuttlingen, Germany) before being processed to remove eventual moisture. Concerning the maximal dispersion and distribution, the ternary biocomposites (PLA/ATBC/L-CNC, PLA/ATBC/CaCO 3 ) and plasticised PLA (PLA/ATBC) were compounded prior to film processing. The laboratory micro-compounder MC 15 HT (Xplore, Sittard, Netherlands) with conical screws, a speed of $100 \mathrm{rpm}$ and a constant temperature profile of $180^{\circ} \mathrm{C}$ was used as the primary processing device. The dispersion and distribution were controlled by the level of torque. Before film processing, the biocomposite compounds (pellets) were again placed in a vacuum oven and dried at $50{ }^{\circ} \mathrm{C}$ for $24 \mathrm{~h}$. The dried pellets were further extruded on the twin-screw extruder MC $15 \mathrm{HT}$ with flat film die (0.2 mm gap size) at a melt temperature of $180{ }^{\circ} \mathrm{C}$ and $80 \mathrm{rpm}$ screw speed. The extruded films were drawn by cooled rolls. The individual compositions of the prepared biocomposite films are listed in Table 1.

Table 1. Sample compositions.

\begin{tabular}{ccccc}
\hline \multirow{2}{*}{ Sample Designation } & \multicolumn{4}{c}{ Composition (wt.\%) } \\
\cline { 2 - 5 } & PLA & ATBC & L-CNC & CaCO $_{3}$ \\
\hline PLA & 100 & - & - & - \\
PLA/ATBC & 90 & 10 & - & - \\
PLA/ATBC/L-CNC & 89 & 10 & 1 & - \\
PLA/ATBC/CaCO & 80 & 10 & - & 10 \\
\hline
\end{tabular}

\subsection{Determination of Ultimate Aerobic Biodegradability under Controlled Composting}

Respirometric tests were conducted using a method adapted from the ISO 14855-1 standard to evaluate the biodegradation kinetics of PLA biocomposite films in composting conditions. This method is based on the measurement of the amount of carbon dioxide evolved during microbial degradation. For this purpose, spirometer ECHO (ECHO d.o.o., Slovenske Konjce, Slovenia) with automatic leak detection, precise mass flow controllers and automatic humidification was used. Biodegradation tests were performed in $2.8 \mathrm{~L}$ cylindrical hermetic vessels containing $100 \mathrm{~mL}$ of demineralised water (for humidification of inoculum), $150 \mathrm{~g}$ of compost and $10 \mathrm{~g}$ of PLA tested films that were trimmed to individual pieces with sizes of about $1 \mathrm{~cm} \times 1 \mathrm{~cm}$. The commonly available compost from the company AGRO CS (Ǩ́kov, Czech Republic) was used in this study. A pH of 6.3 was measured by the Voltcraft PH-100ATC pH meter (VOLCRAFT, Wollerau, Switzerland), while each vessel was determined to have $26.6 \mathrm{~g}$ content of volatile solids $\left(550^{\circ} / 5 \mathrm{~h}\right)$ in the oven CLASIC 3014 (CLASIC CZ, Řevnice, Czech Republic). In accordance with the ISO 14855-1 standard, pebbles and foreign objects bigger than $2 \mathrm{~mm}$ were removed from the compost. Moreover, $50 \%$ humidity water content was adjusted by the halogen moisture analyser Mettler Toledo ${ }^{\mathrm{TM}} \mathrm{HX} 204$ (Mettler Toledo, Columbus, OH, USA). The blank control was composed of only compost. Before use, the correct production of carbon dioxide in a blank 
control vessel was controlled. The inoculum in blank control vessel shall produce between $50 \mathrm{mg}$ and $150 \mathrm{mg}$ of $\mathrm{CO}_{2}$ per gram of volatile solids over the first 10 days (ISO 14855-1). The evaluated value for applied compost was $112 \mathrm{mg}$ of $\mathrm{CO}_{2}$ per gram of volatile solids. Therefore, can be stated that there was significant initial microbial activity. Furthermore, microcrystalline cellulose with particle size of less than $20 \mu \mathrm{m}$ (Sigma-Aldrich, SaintQuentin-Falavier, France) was used as positive reference material to control the correct microbiological activity of the compost. Each biodegradation study was performed in duplicity at a constant temperature of $58{ }^{\circ} \mathrm{C}$. The respirometer was shielded from the light. Every week, glass vessels were opened and the inoculum was stirred to ensure an even distribution of moisture. The percentage of biodegradation was determined from the cumulative amount of released carbon dioxide in accordance with the following equation:

$$
\mathrm{D}_{\mathrm{t}}=\frac{\left(\mathrm{CO}_{2}\right)_{\mathrm{T}}-\left(\mathrm{CO}_{2}\right)_{\mathrm{B}}}{\mathrm{T}_{\mathrm{hCO}}} \cdot 100
$$

where $\left(\mathrm{CO}_{2}\right)_{\mathrm{T}}$ is the cumulative amount of carbon dioxide evolved in the composting vessel containing the test material, $\left(\mathrm{CO}_{2}\right)_{\mathrm{B}}$ is the mean cumulative amount of carbon dioxide evolved in the blank vessels and $\left(\mathrm{T}_{\mathrm{hCO} 2}\right)$ is the theoretical amount of carbon dioxide that can be produced by the test material (all in $\mathrm{g} /$ vessel).

The theoretical amount of carbon dioxide can be determined via the following equation:

$$
\mathrm{T}_{\mathrm{hCO}_{2}}=\mathrm{M}_{\mathrm{TOT}} * \mathrm{C}_{\mathrm{TOT}} \cdot \frac{44}{12}
$$

where $\mathrm{M}_{\mathrm{TOT}}$ is the total dry solids in the test material introduced into the composting vessel at the start of the test (in $\mathrm{g}$ ), $\mathrm{C}_{\mathrm{TOT}}$ is the proportion of total organic carbon in the total dry solids in the test material (in $\mathrm{g} / \mathrm{g}$ ) and 44 and 12 are the molecular mass of carbon dioxide and the atomic mass of carbon, respectively. The individual proportions of total organic carbon of PLA biocomposite components are listed in Table 2.

Table 2. The individual proportions of total organic carbon of PLA biocomposite components.

\begin{tabular}{cc}
\hline Sample Designation & Proportions (\%) \\
\hline PLA & 50.0 \\
ATBC & 59.7 \\
L-CNC & 44.4 \\
$\mathrm{CaCO}_{3}$ & - \\
\hline
\end{tabular}

\subsection{Analysis of Biodegradability in Freshwater Biotype}

Biodegradation of PLA films was also studied in the freshwater biotope. Samples of the same size $(5 \mathrm{~mm} \times 15 \mathrm{~mm})$ were placed in an aquarium containing a steady biotope $(\mathrm{pH}$ 8.1 , temperature $25^{\circ} \mathrm{C}$ ) of aquatic plants, algae, fish, snails, etc. for 3 months. To determine the efficiency of biodegradation, qualitative analyses-including Fourier transform infrared spectroscopy (FT-IR), differential scanning calorimetry (DSC), thermogravimetric analysis (TGA) and the evaluation of surface images taken by scanning electron microscopy (SEM) were performed. Due to the fast defragmentation of ternary biocomposites and plasticized PLA in the initial trial test, the calculation of biodegradation degree through a weight reduction was not considered. Another reason was negative influence of conditioning on microbial activity. Consequently, the samples were taken from biotope only for trimming of specimens for qualitative analyses. Trimmed specimens were conditioned $\left(25^{\circ} / 96 \mathrm{~h}\right)$ before characterisation. The results from the introduced analyses were evaluated from 3 measurements. As the data set was small, only average values have been provided; thus, standard deviation has not been specified. 


\subsubsection{Fourier Transform Infrared Spectroscopy (FT-IR)}

The chemical changes of the PLA films were analysed using an infrared spectrometer Nicolet iS10 (Thermo Fisher Scientific, Waltham, MA, USA) in Attenuated Total Reflectance (ATR) mode and equipped with a diamond crystal. The FTIR-ATR spectra were recorded in the range of $400-4000 \mathrm{~cm}^{-1}$ by averaging 64 scans and using a resolution of $2 \mathrm{~cm}^{-1}$.

\subsubsection{Differential Scanning Calorimetry (DSC)}

Thermal properties were determined in a calorimeter DSC 1/ 700 (Mettler Toledo, Greifensee, Switzerland) under a constant nitrogen flow of $50 \mathrm{~mL} / \mathrm{min}$. Samples of approximately $5 \mathrm{mg}$ were prepared from the cross-section of the PLA films and placed in an aluminium pan before being sealed and placed in the DSC chamber. The samples were heated from $0{ }^{\circ} \mathrm{C}$ to $200{ }^{\circ} \mathrm{C}$ with a heating rate of $10^{\circ} \mathrm{C} / \mathrm{min}$. Further isothermal conditions were kept for $180 \mathrm{~s}$ to remove previous thermal history and then cooled again $\left(10^{\circ} \mathrm{C} / \mathrm{min}\right)$. Primary glass transition temperature $\left(\mathrm{T}_{\mathrm{g}}\right)$, cold crystallisation temperatures and enthalpies $\left(\mathrm{T}_{\mathrm{cc}}, \Delta \mathrm{H}_{\mathrm{cc}}\right)$ and melting temperatures and enthalpies $\left(\mathrm{T}_{\mathrm{p}, \mathrm{m}}, \Delta \mathrm{H}_{\mathrm{m}}\right)$ were evaluated. The degree of crystallinity $\left(\mathrm{X}_{\mathrm{C}}\right)$ was determined through the following equation, where $\Delta \mathrm{H}_{\mathrm{m}}^{\mathrm{O}}$ is the melting enthalpy of $100 \%$ crystalline PLA $(93.1 \mathrm{~J} / \mathrm{g})[2,29]$ and $\mathrm{w}_{\mathrm{m}}$ is the mass fraction of PLA in the composites.

$$
\mathrm{X}_{\mathrm{C}}=\frac{\Delta \mathrm{H}_{\mathrm{m}}-\Delta \mathrm{H}_{\mathrm{pc}}-\Delta \mathrm{H}_{\mathrm{cc}}}{\Delta \mathrm{H}_{\mathrm{m}}^{\mathrm{O}} \cdot \mathrm{w}_{\mathrm{m}}} \cdot 100
$$

\subsubsection{Thermogravimetric Analysis (TGA)}

Thermal degradation was performed using TGA via a TGA2 instrument (Mettler Toledo, Greifensee, Switzerland). The samples prepared from the cross-section ( $5 \pm 0.5 \mathrm{mg})$ were heated from $50^{\circ} \mathrm{C}$ to $600^{\circ} \mathrm{C}$ under an $\mathrm{N}_{2}$ atmosphere at the heating ramp of $10^{\circ} \mathrm{C} / \mathrm{min}$. The decomposition temperature was determined at $5 \%$ weight loss ( $\mathrm{T}_{5} \%$ and $50 \%$ weight loss $\left(\mathrm{T}_{50 \%}\right)$.

\subsubsection{Scanning Electron Microscopy (SEM) Images}

The surface changes of PLA films were examined by field emission scanning electron microscopy (FE-SEM) using the Carl Zeiss ULTRA (Carl Zeiss, Oberkochen, Germany) microscope under an accelerated voltage of $5 \mathrm{kV}$. The trimmed samples was directly after conditioning $\left(25^{\circ} / 96 \mathrm{~h}\right)$ fixed with carbon adhesive tape on aluminium holder and coated with $1 \mathrm{~nm}$ of platinum using Q150R ES (Quorum Technologies Ltd., Lewes, UK).

\section{Results and Discussion}

\subsection{Determination of Ultimate Aerobic Biodegradability under Controlled Composting}

The tested PLA films and reference microcrystalline cellulose (MCC) powder were exposed to controlled composting conditions. The evaluated biodegradation curves are shown in Figure 1. The MCC started intensively degrading after three days of the induction period (lag phase). The biodegradation degree was $72 \%$ after 45 days, which confirms the proper microbial activity of the used compost and the validity of the results (ISO 14855-1). Furthermore, an increased biodegradation rate following the addition of $10 \mathrm{wt} . \%$ ATBC plasticiser was observed when compared to neat PLA. The induction period of plasticised PLA (PLA/ATBC) was eight days shorter than for neat PLA films. The level of biodegradation after 30 days was $6 \%$ for neat PLA and $16 \%$ for PLA/ATBC. While the biodegradation of PLA/ATBC achieved a level of $97 \%$ (starting of the plateau phase) after 75 days, the biodegradation level of neat PLA was just $42 \%$ and according to the curse of biodegradation had not yet been finished. The low mineralisation rate (40 days lag phase, $90 \%$ biodegradation level within 120 days) of neat PLA exposed to aerobic thermophilic biodegradation was also reported by Itävaara et al. [20]. In the first 30 days, biodegradation results similar to those for plasticised PLA were obtained for ternary biocomposites based on PLA/ATBC/L-CNC. Since then, a slightly lower biodegradation rate 
was detected. The achieved biodegradation level after 75 days was $90 \%$. The reason behind this phenomenon could be the inhibition of microbial activity due to the lignin coating of CNC. Yang et al. [30] and Micales et al. [31] reported that lignin inhibits the degradation of cellulose. The greatest influence on the biodegradation process was observed in ternary biocomposites containing $\mathrm{CaCO}_{3}$ nucleation agents. The induction period was 19 days shorter than for neat PLA films. A 58\% level of biodegradation was achieved in 30 days, with $100 \%$ biodegradation and a plateau distribution recorded by the end of the experiment. This supports the findings of Hedge et al. [32], who observed increased biodegradation rates during anaerobic conditions after applying $\mathrm{CaCO}_{3}$ at low concentrations. The reason behind this could be that releasing $\mathrm{CaCO}_{3}$ to the biodegradation medium offers buffering action and helps to prevent the acidification of the $\mathrm{pH}$ [23] that could result from the degradation of a polymer matrix into lactic and succinic acids [32]. Regarding this point, the $\mathrm{pH}$ of individual composts was evaluated at the end of the experiment (see Table 3). In contrast to the findings for the blank vessels, an increase in the alkaline level of the compost was observed due to the introduction of PLA-based films. Greater increases were observed for plasticised PLA (PLA/ATBC) and ternary biocomposites (PLA/ATBC/CaCO 3 , PLA/ATBC/L-CNC). Another aspect that can influence the biodegradation rate is the surface treatment of $\mathrm{CaCO}_{3}$, as fatty acid-based sizing agents are commonly applied to prevent their agglomeration [33]. The fatty acid causes a chemical reaction with the ester linkage of PLA, which evokes chain scission and induces thermal degradation [34].

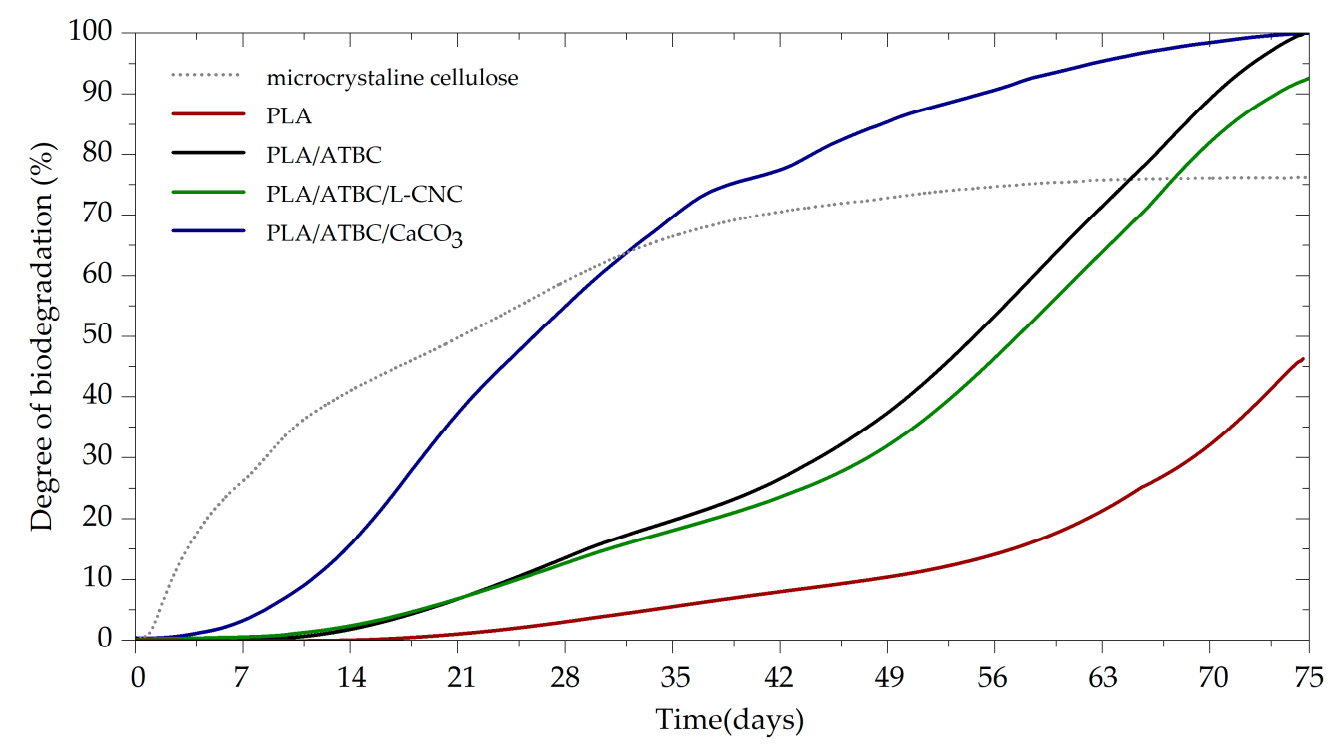

Figure 1. Biodegradation curves of PLA biocomposites under controlled composting ISO 18455-1.

Table 3. Evaluated $\mathrm{pH}$ of compost at the end of the experiment.

\begin{tabular}{cc}
\hline Sample Designation & $\mathbf{p H}(-)$ \\
\hline Blank vessel & 6.5 \\
PLA & 7.0 \\
PLA/ATBC & 7.3 \\
PLA/ATBC/L-CNC & 7.2 \\
PLA/ATBC/CaCO & 7.5 \\
\hline
\end{tabular}

\subsection{Analysis of Biodegradability in Freshwater Biotope}

\subsubsection{Fourier Transform Infrared Spectroscopy (FT-IR)}

The ATR-FT-IR spectra of PLA-based films (Figure 2a) showed a typical absorption band corresponding to the $\mathrm{C}=\mathrm{O}$ stretching of ester groups at $1747 \mathrm{~cm}^{-1}$, asymmetric and symmetric $\mathrm{CH}_{3}$ stretching at $2995 \mathrm{~cm}^{-1}$ and $2945 \mathrm{~cm}^{-1}$. Furthermore, the $\mathrm{C}-\mathrm{O}$ stretching 
bands of $\mathrm{CH}-\mathrm{O}$ at $1180 \mathrm{~cm}^{-1}$ and $\mathrm{O}-\mathrm{C}=\mathrm{O}$ groups at $1127 \mathrm{~cm}^{-1}, 1080 \mathrm{~cm}^{-1}$ and $1043 \mathrm{~cm}^{-1}$, respectively, were observed. The same absorption band characteristic was detected by Sessini et al. [35], Lee et al. [36], Weng et al. [37] and Amorin et al. [38]. Moreover, bending frequencies for $\mathrm{CH}_{3}$ have bends identified at $1452 \mathrm{~cm}^{-1}, 1382 \mathrm{~cm}^{-1}$ and $1359 \mathrm{~cm}^{-1}$, as well as bends related to the $\mathrm{C}=\mathrm{O}$ double-bound around $700 \mathrm{~cm}^{-1}$ [39]. Any significant differences were not detected in the absorption bands of plasticised PLA (PLA/ATBC) and PLA/ATBC/L-CNC ternary biocomposites. However, an increased peak height ratio of PLA/ATBC $/ \mathrm{CaCO}_{3}$ ternary biocomposites around $1450 \mathrm{~cm}^{-1}$ and $872 \mathrm{~cm}^{-1}$ could be seen, as well as a decreased peak height ratio around $1750 \mathrm{~cm}^{-1}$. From the absorption band of PLA films exposed to 3 months of degradation in freshwater, it is evident that FTIR peak height ratios significantly decreased. Consequently, it can be stated that chemical changes were evoked by the degradation process. Moreover, a new peak at around $3400 \mathrm{~cm}^{-1}$ (Figure 2b) indicates the occurrence of hydrolysis degradation [40]. When comparing the neat PLA film spectra with PLA biocomposites based on ATBC, $\mathrm{CaCO}_{3}$ and $\mathrm{L}-\mathrm{CNC}$, the smaller decrease in peak intensity is evident. The lowest peak height ratios and the greatest chemical changes were observed in the PLA biocomposite containing the ATBC plasticiser and $\mathrm{CaCO}_{3}$ nucleating agents. To assess differences in degradation kinetics, the peak intensities at $1080 \mathrm{~cm}^{-1}, 1127 \mathrm{~cm}^{-1}, 1359 \mathrm{~cm}^{-1}, 1382 \mathrm{~cm}^{-1}, 1452 \mathrm{~cm}^{-1}, 1747 \mathrm{~cm}^{-1}$ and $3400 \mathrm{~cm}^{-1}$ are compared in Table 4 . Considerable differences in the kinetics of degradation can be seen from the evaluated peaks. The neat PLA showed a significant decrease in FTIR peak height ratios after only 3 months of degradation. However, an intensive decrease in peak height was observed for plasticised PLA after 2 months of exposition. The PLA/ATBC/L-CNC biopolymer showed increased resistance to degradation in the first month. Since then, an intensive decrease in peak height ratios was also observed. The greatest decrease of absorption bands was observed in ternary biocomposites based on PLA/ATBC $/ \mathrm{CaCO}_{3}$ after 2 months of degradation.

(a) 1.0

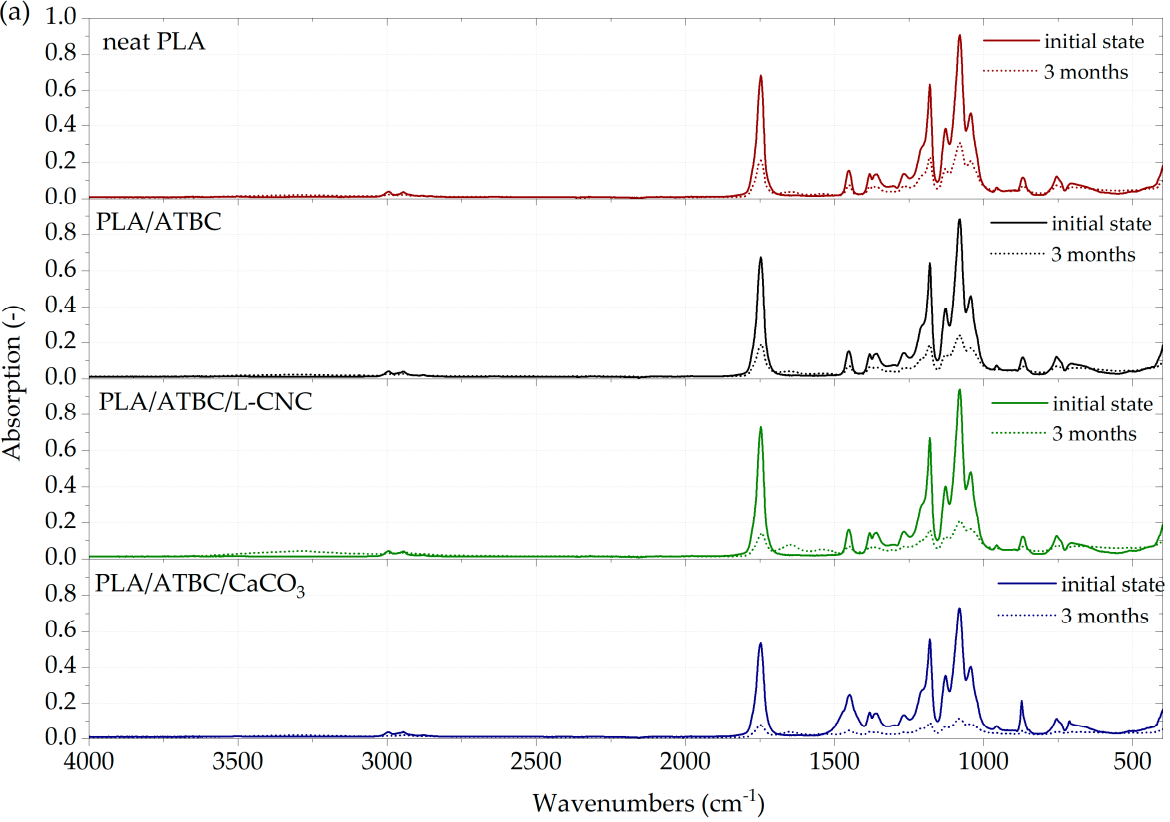

(b)

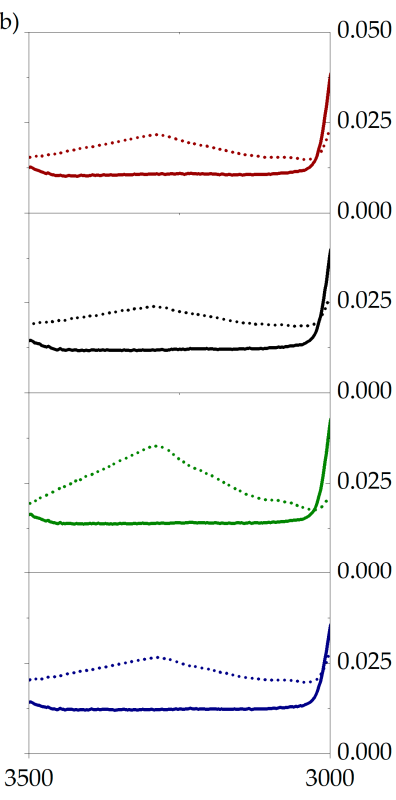

Figure 2. FTIR spectra of PLA biocomposites. (a) At initial state and after three months of biodegradation in freshwater biotope. (b) Occurrence of hydrolysis degradation. 
Table 4. Peak intensity of PLA biocomposites exposed to 3 months of biodegradation in freshwater biotope.

\begin{tabular}{|c|c|c|c|c|c|c|c|c|}
\hline $\begin{array}{c}\text { Sample } \\
\text { Designation }\end{array}$ & $\begin{array}{l}\text { Exposition } \\
\text { Time (Months) }\end{array}$ & $3400 \mathrm{~cm}^{-1}$ & $1747 \mathrm{~cm}^{-1}$ & $1452 \mathrm{~cm}^{-1}$ & $1382 \mathrm{~cm}^{-1}$ & $1359 \mathrm{~cm}^{-1}$ & $1127 \mathrm{~cm}^{-1}$ & $1080 \mathrm{~cm}^{-1}$ \\
\hline \multirow{4}{*}{ PLA } & Initial state & 0.01 & 0.68 & 0.15 & 0.14 & 0.14 & 0.38 & 0.91 \\
\hline & 1 & 0.02 & 0.53 & 0.15 & 0.13 & 0.13 & 0.34 & 0.73 \\
\hline & 2 & 0.02 & 0.38 & 0.11 & 0.10 & 0.10 & 0.27 & 0.56 \\
\hline & 3 & 0.02 & 0.21 & 0.07 & 0.07 & 0.7 & 0.16 & 0.31 \\
\hline \multirow{4}{*}{ PLA/ATBC } & Initial state & 0.01 & 0.68 & 0.15 & 0.14 & 0.14 & 0.39 & 0.89 \\
\hline & 1 & 0.02 & 0.57 & 0.15 & 0.13 & 0.13 & 0.36 & 0.77 \\
\hline & 2 & 0.02 & 0.22 & 0.08 & 0.08 & 0.07 & 0.16 & 0.29 \\
\hline & 3 & 0.02 & 0.19 & 0.07 & 0.07 & 0.06 & 0.13 & 0.29 \\
\hline \multirow{4}{*}{$\begin{array}{l}\mathrm{PLA} / \mathrm{ATBC} / \mathrm{L}- \\
\mathrm{CNC}\end{array}$} & Initial state & 0.01 & 0.72 & 0.15 & 0.14 & 0.15 & 0.4 & 0.93 \\
\hline & 1 & 0.02 & 0.64 & 0.15 & 0.14 & 0.14 & 0.38 & 0.86 \\
\hline & 2 & 0.02 & 0.22 & 0.08 & 0.07 & 0.07 & 0.15 & 0.28 \\
\hline & 3 & 0.03 & 0.14 & 0.07 & 0.08 & 0.06 & 0.12 & 0.22 \\
\hline \multirow{4}{*}{$\mathrm{PLA} / \mathrm{ATBC} / \mathrm{CaCO}_{3}$} & Initial state & 0.01 & 0.54 & 0.24 & 0.15 & 0.14 & 0.35 & 0.73 \\
\hline & 1 & 0.02 & 044 & 0.21 & 0.13 & 0.13 & 0.31 & 0.63 \\
\hline & 2 & 0.02 & 0.15 & 0.07 & 0.06 & 0.06 & 0.12 & 0.2 \\
\hline & 3 & 0.02 & 0.08 & 0.05 & 0.04 & 0.04 & 0.07 & 0.12 \\
\hline
\end{tabular}

\subsubsection{Differential Scanning Calorimetry (DSC)}

The results for non-isothermal conditions during the first heating step were evaluated for processed samples (initial state) and samples degraded in a fresh water biotope over 3 months. The effect of processing parameters and the promoting effect of ATBC and / or nucleated agents $\left(\mathrm{L}-\mathrm{CNC}, \mathrm{CaCO}_{3}\right)$ on the thermal parameters and crystallisation behaviour were investigated. As can be seen from the DSC curves in Figure 3, neat PLA, plasticised PLA (PLA/ATBC) and related ternary biocomposites (PLA/ATBC/ $\mathrm{CaCO}_{3}$, PLA/ATBC/L-CNC) exhibited characteristic glass transition $\left(\sim 37-64{ }^{\circ} \mathrm{C}\right)$, cold crystallisation $\left(\sim 79-116^{\circ} \mathrm{C}\right)$ and melting $\left(\sim 139-171^{\circ} \mathrm{C}\right)$. A summary of the transition temperatures and related enthalpies is given in Table 5 . The shift of the glass transition temperature $\left(\mathrm{T}_{\mathrm{g}}\right)$ towards a lower temperature $\left(46.7^{\circ} \mathrm{C}\right)$ compared to neat PLA $\left(62^{\circ} \mathrm{C}\right)$ could be observed after introducing $10 \mathrm{wt} . \%$ of ATBC to processed samples. This shift was caused by the decrease in intramolecular binding forces due to the addition of low molecular weight plasticiser, which increased the intermolecular distance and also resulted in an increase in macromolecular chain mobility [3]. Consequently, cold crystallisation temperature $\left(\mathrm{T}_{\mathrm{cc}}\right)$ and primary melting temperature $\left(\mathrm{T}_{\mathrm{pm}}\right)$ also reached lower values compared to neat PLA. Furthermore, dual melting peaks could be observed after the introduction of ATBC. Wu et al. [41] observed that broad cold crystallisation indicates the formation of multi-population lamella with different layer thicknesses that cause the dual melting peaks. These dual melting peaks can be ascribed to the formation of different crystalline structures. The thermal parameters during the non-isothermal processing conditions of PLA allow for the formation of two polymorphs: $\alpha$ and $\alpha^{\prime}$-crystallites. The non-isothermal crystallisation from relaxed melt at a temperature above $120^{\circ} \mathrm{C}$ led to the formation of $\alpha$-crystallites. Between $100{ }^{\circ} \mathrm{C}$ and $120^{\circ} \mathrm{C}$, both forms crystallise in coexistence; below $100{ }^{\circ} \mathrm{C}$, only metastable $\alpha^{\prime}$-crystallites grow [42]. The packing density of $\alpha^{\prime}$-crystallites is lower due to conformational disorder. During the subsequent heating, $\alpha^{\prime}$-crystallites transformed into more stable $\alpha$-crystallites at a temperature of around $150{ }^{\circ} \mathrm{C}$ [43]. The introduction of $1 \mathrm{wt}$ \% L-CNC (PLA/ATBC/L-CNC) caused a slight increase in $\mathrm{T}_{\mathrm{g}}$ and $\mathrm{T}_{\mathrm{cc}}$ when compared to the plasticised system (PLA/ATBC). In our previous study [44], we reported the synergistic effect of $1 \mathrm{wt} . \% \mathrm{~L}-\mathrm{CNC}$ and $10 \mathrm{wt} . \%$ ATBC on the crystallisation of the PLLA matrix during injection moulding. The nucleation efficiency of L-CNC on the PLA matrix has also been reported by Gupta et al. [15]. However, our results did not correlate with these previous reports. The fast cooling during the processing of ternary PLA/ATBC/L-CNC films-as well as different PLA matrices that contain more D-lactic acid than those used 
in previous reports-could be ascribed to this phenomenon. The addition of $10 \mathrm{wt} . \%$ of $\mathrm{CaCO}_{3}\left(\mathrm{PLA} / \mathrm{ATBC} / \mathrm{CaCO}_{3}\right)$ caused a further decrease in $\mathrm{T}_{\mathrm{g}}\left(42.4^{\circ} \mathrm{C}\right)$ when compared to plasticised PLA $\left(46.7^{\circ} \mathrm{C}\right)$. The cold crystallisation temperature remained unchanged when compared to plasticised PLA. In contrast to the research of Suksut et al. [45], this indicates that $\mathrm{CaCO}_{3}$ does not function as a proper nucleating agent in the fast cooling conditions of the PLA matrix.

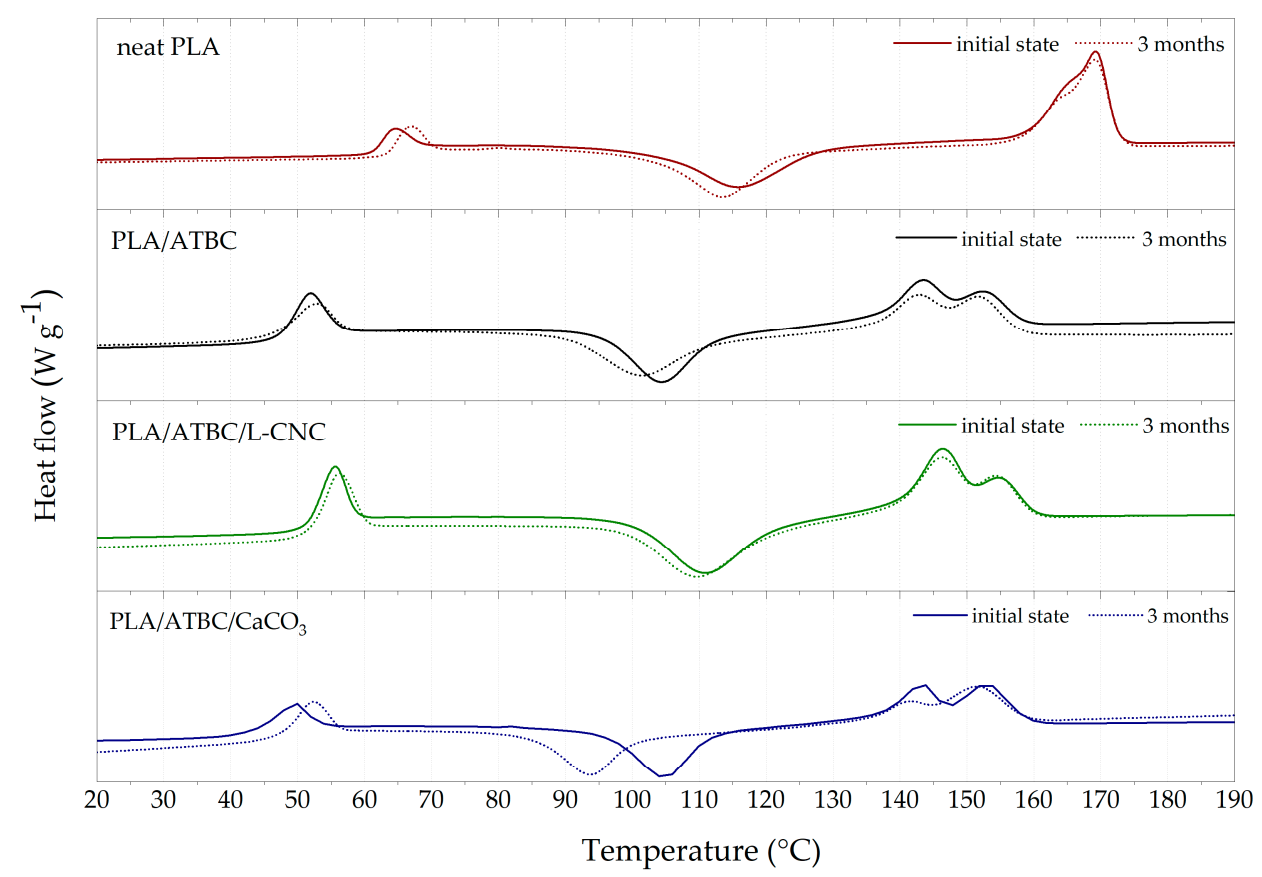

Figure 3. Thermal analysis (DSC) curves of PLA biocomposites at initial state and after three months of biodegradation in freshwater biotope.

Table 5. Thermal analysis (DSC) data of PLA biocomposites exposed to 3 months of biodegradation in freshwater biotope.

\begin{tabular}{|c|c|c|c|c|c|c|c|c|c|}
\hline $\begin{array}{c}\text { Sample } \\
\text { Designation }\end{array}$ & $\begin{array}{c}\text { Exposition Time } \\
\text { (Months) }\end{array}$ & $\mathrm{T}_{\mathrm{g}}\left({ }^{\circ} \mathrm{C}\right)$ & $\mathrm{T}_{\mathrm{cc}}\left({ }^{\circ} \mathrm{C}\right)$ & $\begin{array}{l}\Delta \mathrm{H}_{\mathrm{cc}} \\
(\mathrm{J} / \mathrm{g})\end{array}$ & \multicolumn{2}{|c|}{$\mathrm{T}_{\mathrm{pm}}\left({ }^{\circ} \mathrm{C}\right)$} & $\begin{array}{c}\Delta H_{m} \\
(J / g)\end{array}$ & $\begin{array}{c}\Delta \mathrm{H}_{\mathrm{m} \alpha^{\prime}} \\
(\mathrm{J} / \mathrm{g})\end{array}$ & $X_{C}(\%)$ \\
\hline \multirow{4}{*}{ PLA } & Initial state & 62.0 & 115.7 & 35.62 & \multicolumn{2}{|c|}{169.2} & 36.3 & - & 0.8 \\
\hline & 1 & 63.1 & 115.2 & 33.98 & \multicolumn{2}{|c|}{170.6} & 37.7 & - & 4.0 \\
\hline & 2 & 63.4 & 114.2 & 32.20 & \multicolumn{2}{|c|}{170.1} & 36.6 & - & - \\
\hline & 3 & 64.0 & 113.5 & 31.02 & \multicolumn{2}{|c|}{169.4} & 36.6 & - & - \\
\hline \multirow{4}{*}{ PLA/ATBC } & Initial state & 46.7 & 104.5 & 22.64 & 143.7 & 152.5 & 26.1 & 16.4 & 4.2 \\
\hline & 1 & 37.6 & 87.3 & 20.63 & 139.7 & 151.2 & 25.9 & 9.4 & 6.3 \\
\hline & 2 & 38.8 & 89.3 & 20.94 & 139.1 & 149.7 & 26.4 & 10.0 & - \\
\hline & 3 & 45.1 & 101.5 & 22.78 & 142.8 & 151.8 & 26.0 & 14.6 & - \\
\hline \multirow{4}{*}{$\begin{array}{c}\mathrm{PLA} / \mathrm{ATBC} / \mathrm{L}- \\
\mathrm{CNC}\end{array}$} & Initial state & 51.2 & 110.8 & 25.70 & 146.5 & 154.9 & 25.8 & 17.7 & 0.1 \\
\hline & 1 & 52.5 & 110.5 & 26.01 & 147.2 & 155.1 & 25.8 & 18.2 & 0.0 \\
\hline & 2 & 52.8 & 110.8 & 26.77 & 147.7 & 155.3 & 26.3 & 18.2 & - \\
\hline & 3 & 51.1 & 109.3 & 26.52 & 146.4 & 154.6 & 25.8 & 16.9 & - \\
\hline \multirow{4}{*}{$\mathrm{PLA} / \mathrm{ATBC} / \mathrm{CaCO}_{3}$} & Initial state & 42.4 & 104.7 & 22.51 & 143.4 & 153.0 & 24.7 & 12.9 & 2.9 \\
\hline & 1 & 38.4 & 81.5 & 15.81 & 137.4 & 149.0 & 26.0 & 6.8 & 13.7 \\
\hline & 2 & 37.4 & 78.5 & 15.96 & 140.3 & 150.1 & 22.9 & 7.9 & - \\
\hline & 3 & 46.7 & 93.8 & 19.15 & 141.2 & 151.4 & 22.4 & 9.1 & - \\
\hline
\end{tabular}


Furthermore, an increase in $\mathrm{T}_{\mathrm{g}}$ during the three months of degradation for neat PLA could be observed. This indicates the crystallinity degree increased within this time. In contrast, plasticised PLA presented a decrease in $T_{g}$ within the first two months. This could be ascribed to the chain shortening (hydrolysis reaction) of macromolecular chains within the amorphous region. An increase in $\mathrm{T}_{\mathrm{g}}$ after three months of degradation within the freshwater biotope was observed. This phenomenon could be related to the degradation of the less accessible semicrystalline region over time and the releasing of the ATBC plasticiser and oligomeric PLA in the environment. A correlation in the shift of $\mathrm{T}_{\mathrm{cc}}$ towards lower temperatures could also be observed. No significant changes within thermal transitions were observed during the degradation time of ternary PLA/ATBC/L-CNC films. This may be because of the inhibition of microbial activity due to the lignin coating of $\mathrm{CNC}$ as well as the steric hindrance of plasticised PLA. During the degradation of PLA/ATBC $/ \mathrm{CaCO}_{3}$ films, $\mathrm{T}_{\mathrm{g}}$ again decreased within the first two months and increased after the third month. This also correlates with the changes in $\mathrm{T}_{\mathrm{Cc}}$. Thus, the same mechanism of degradation is believed to exist as in plasticised PLA, the leaching of oligomers and ATBC in the environment. This has been further supported by $\mathrm{CaCO}_{3}$ and its fatty acids.

The crystallinity degree $\left(X_{C}\right)$ calculations shown in Table 5 can be considered authoritative only in the initial state after processing and, at most, during the first month of degradation. The later measured samples were degraded to the extent that we cannot confirm the exact weight content of additives. Consequently, the results for the second and third months were not described.

\subsubsection{Thermogravimetric Analysis (TGA)}

The results of TGA are shown in Figure 4 and summarised in Table 6. A significant decrease in the thermal stability (initial decomposition temperature $\mathrm{T}_{5} \%$ ) of PLA films was observed with the addition of the ATBC plasticiser. Similar results were observed by Maiza et al. [3] and Sessini et al. [35]. Nelson et al. [46] reported that a higher degree of crystallinity is directly involved in the higher thermal stability of L-CNCs. Our previous study [47] found that the presence of L-CNC in PLA increased the crystallinity degree, resulting in increased thermal stability. As stated in the DSC section, the low concentration (1 wt.\%) of L-CNC did not increase the crystallinity degree in the chosen processing conditions. Despite this, an increase in the thermal stability of the PLA/ATBC/L-CNC biocomposites was observed. This could be due to the steric hindrance of plasticised PLA macromolecular chains by the high volume of L-CNC particles and their huge surface area. Nekhamanurak et al. [34] reported the profound impact of the fatty acid treatment of $\mathrm{CaCO}_{3}$ on the thermal stability of $\mathrm{PLA} / \mathrm{CaCO}_{3}$ biocomposites. The chemical reaction between the fatty acid and ester linkage of PLA caused chain scission and induced thermal degradation. This is supported by the obtained results. The presence of $10 \mathrm{wt} . \%$ of $\mathrm{CaCO}_{3}$ in plasticised PLA caused the greatest decrease in thermal stability. The initial degradation temperature $\left(\mathrm{T}_{5} \%\right)$ decreased around $61{ }^{\circ} \mathrm{C}$ and temperature at the midpoint $\left(\mathrm{T}_{50} \%\right)$ around $41^{\circ} \mathrm{C}$. When the TGA results of PLA films exposed to freshwater biodegradation are compared, similar conclusions about the influence of additives can be made as for the thermophilic composting process. The minuscule decrease in the thermal degradation temperatures of neat PLA is a sign of biodegradation resistance. This supports the results of Itävaara et al. [20], who observed very slow PLA biodegradation in an aquatic test at room temperature. Kallel et al. [28] reported that the addition of plasticiser evokes faster hydrolysis and hydrolytic attack by a microorganism. Consequently, a significant decrease in the initial thermal degradation temperature was observed for PLA/ATBC. Moreover, the $\mathrm{PLA} / \mathrm{ATBC} / \mathrm{CaCO}_{3}$ biocomposites showed a significant decrease in initial decomposition temperature. This was due to intensive hydrolysis and surface erosion evident even after one month of exposition to freshwater biodegradation. 


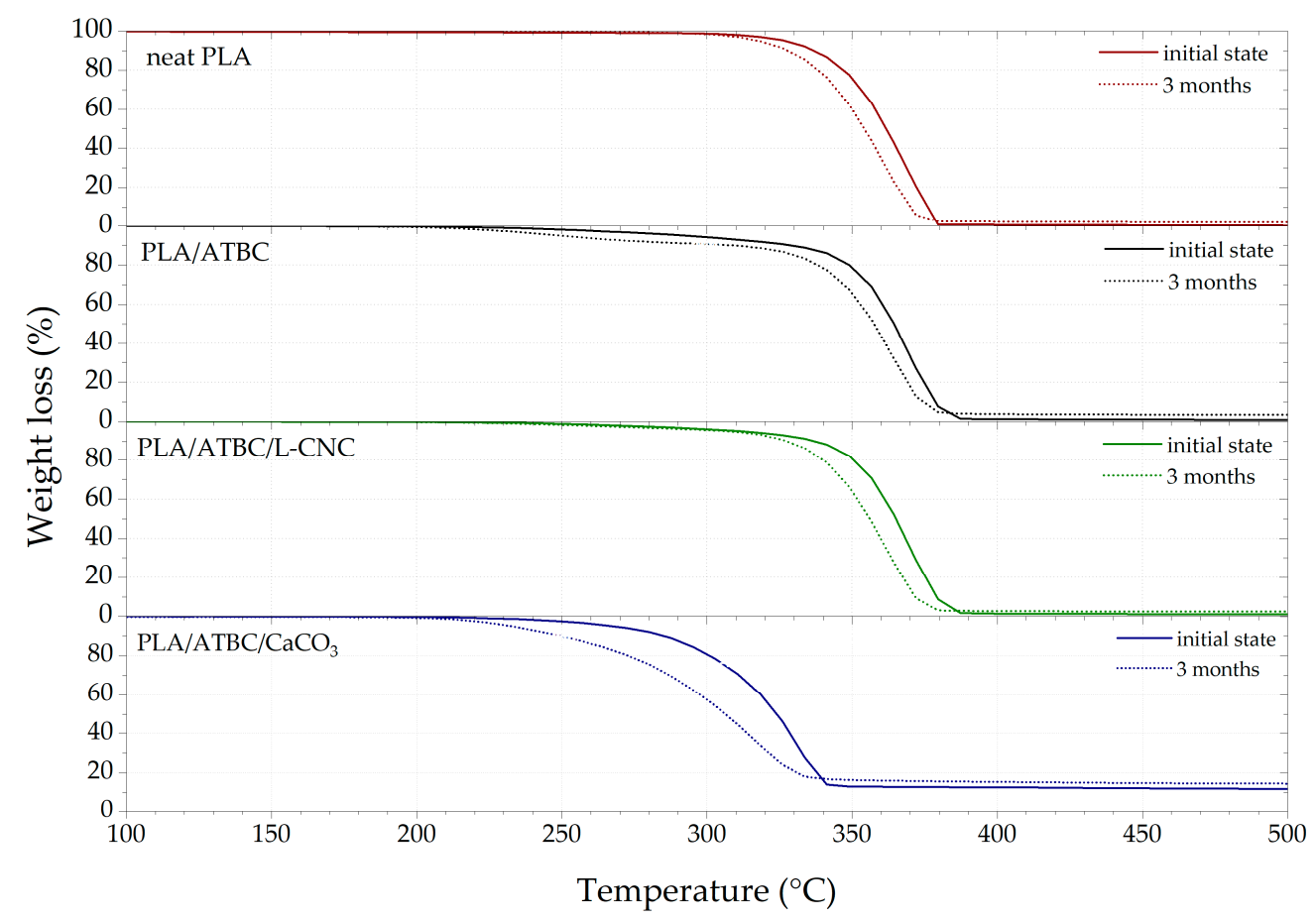

Figure 4. Thermogravimetric analysis (TGA) curves of PLA biocomposites at initial state and after 3 months of biodegradation in freshwater biotope.

Table 6. Thermogravimetric analysis (TGA) data of PLA biocomposites exposed to three months of biodegradation in freshwater biotope.

\begin{tabular}{ccccccccc}
\hline \multirow{2}{*}{$\begin{array}{c}\text { Sample } \\
\text { Designation }\end{array}$} & \multicolumn{1}{c}{ Initial State } & \multicolumn{2}{c}{ Exposition Time (Months) } \\
& $\mathbf{T}_{\mathbf{5}} \mathbf{( \% )}$ & $\mathbf{T}_{\mathbf{5 0}} \mathbf{( \% )}$ & $\mathbf{T}_{\mathbf{5}} \mathbf{( \% )}$ & $\mathbf{T}_{\mathbf{5 0}} \mathbf{( \% )}$ & $\mathbf{T}_{\mathbf{5}} \mathbf{( \% )}$ & $\mathbf{T}_{\mathbf{5 0}} \mathbf{( \% )}$ & $\mathbf{T}_{\mathbf{5}} \mathbf{( \% )}$ & $\mathbf{T}_{\mathbf{5 0}} \mathbf{( \% )}$ \\
\hline PLA & 329.2 & 361.9 & 326.8 & 360.5 & 326.7 & 360.0 & 319.1 & 353.9 \\
PLA/ATBC & 294.3 & 364.3 & 282.2 & 359.9 & 274.5 & 357.8 & 250.9 & 356.8 \\
PLA/ATBC/L- & 312.9 & 364.9 & 312.4 & 361.2 & 309.7 & 359.1 & 308.1 & 355.6 \\
CNC & 267.8 & 320.7 & 247.1 & 299.9 & 233.8 & 299.5 & 233.5 & 299.4 \\
\hline PLA/ATBC/CaCO & 26.9 &
\end{tabular}

\subsubsection{Scanning Electron Microscopy (SEM) Images}

The SEM images of the surfaces of PLA films after processing and by the end of the freshwater biodegradation process (after three months) are shown in Figure 5. The produced PLA films showed smooth surfaces. Significant differences in degradation were observed between neat PLA films and PLA films containing ATBC plasticisers and/or nucleation agents ( $\left.\mathrm{L}-\mathrm{CNC}, \mathrm{CaCO}_{3}\right)$. Neat PLA films showed a relatively smooth surface with a small number of cavities. In contrast, PLA films with plasticiser showed a rough surface with many eroded pinholes. The PLA polymers had the characteristics of bulk (homogenous) degradation [18] and the continuous decreasing of weight and thickness without releasing carboxyl acid and hydroxyl by-products [48] until the critical sample thickness was achieved [49]. The increased molecular mobility following the addition of the ATBC plasticiser caused faster hydrolysis, which increased the rate of hydrolytic attack, surface erosion and microbial enzymatic degradation. Kallel et al. [28] reported increased surface erosion as a result of faster hydrolysis and higher microbial enzyme activity following the exposition of a PLA/PEG blend to an aerobic liquid medium. 

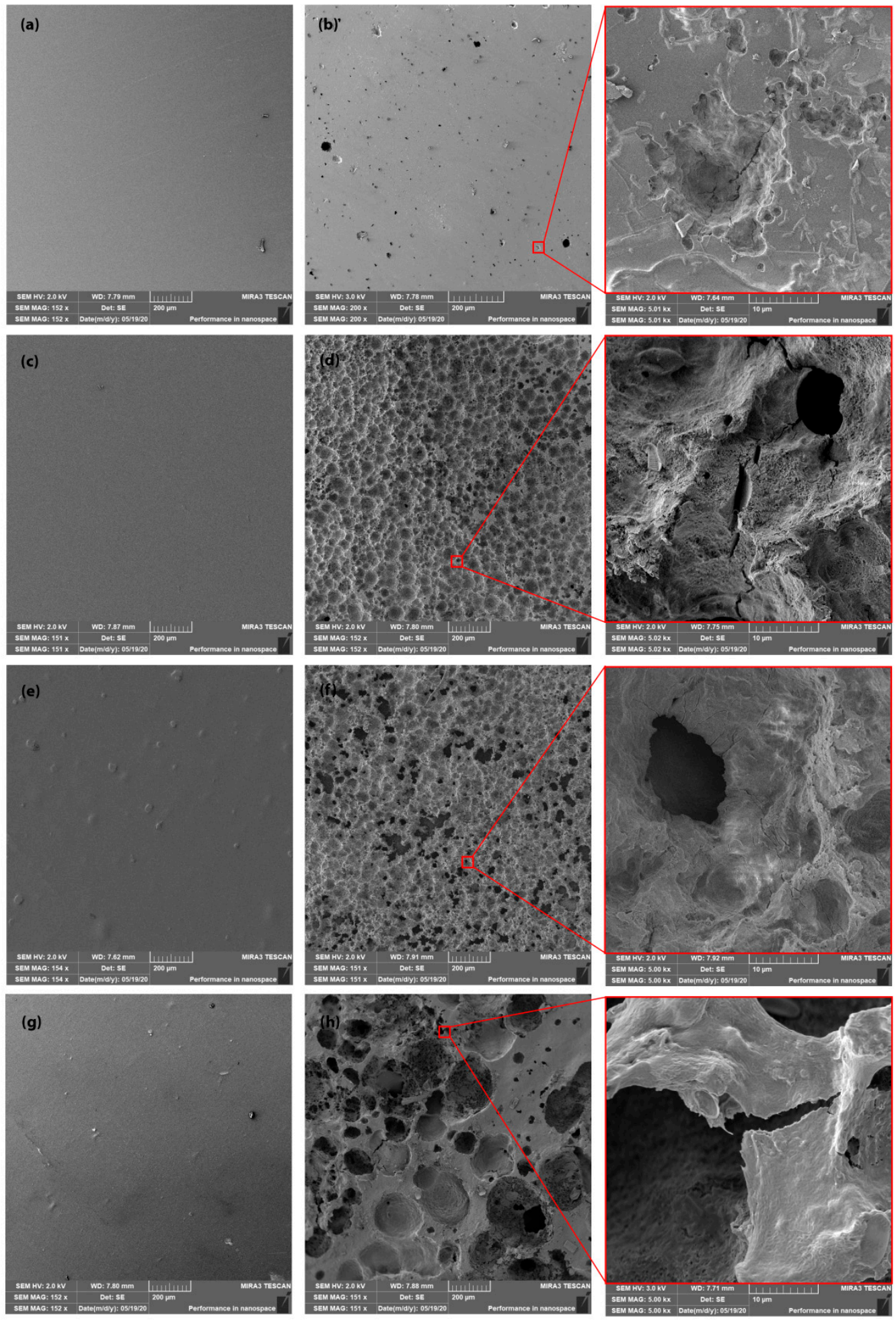

Figure 5. SEM images of (a) neat PLA film at initial state, (b) neat PLA film after three months of biodegradation, (c) PLA/ATBC at initial state, (d) PLA/ATBC after three months of biodegradation, (e) PLA/ATBC/L-CNC at initial state, (f) PLA/ATBC/L-CNC after three months of biodegradation, (g) $\mathrm{PLA} / \mathrm{ATBC} / \mathrm{CaCO}_{3}$ at initial state and (h) PLA $/ \mathrm{ATBC} / \mathrm{CaCO}_{3}$ after three months of biodegradation. 
As previously stated, the considerable effect of the lignin coating of CNC in PLA/ATBC/ L-CNC improved thermal stability and inhibited degradation in the first month of freshwater biotope conditions. However, when the SEM images of the PLA/ATBC biopolymers and PLA/ATBC/L-CNC surfaces by the end of the biodegradation experiment (after three months) are compared, no significant differences can be observed. The largest pinholes and highest surface roughness were observed in the PLA/ATBC $/ \mathrm{CaCO}_{3}$ material combination. The ATBC plasticiser and fatty acid treatment of $\mathrm{CaCO}_{3}$ resulted in intensive hydrolysis that increased surface erosion and caused the releasing of $\mathrm{CaCO}_{3}$. The release of the $\mathrm{CaCO}_{3}$ additive led to a further increase in surface roughness, which ensured faster hydrolytic and enzymatic degradation of this biocomposite.

\section{Conclusions}

The influence of additives such as natural-based plasticiser $\mathrm{ATBC}, \mathrm{CaCO}_{3}$ and $\mathrm{L}-\mathrm{CNC}$ on the biodegradation of PLA biocomposite films in thermophilic compost and freshwater biotope has been studied. Very low biodegradation rates were observed for neat PLA. The application of ATBC at a $10 \mathrm{wt} . \%$ loading significantly increased the induction period and the level of biodegradation of PLA films in controlled composting (ISO 14855-1). Slightly lower biodegradation rates were detected in ternary biocomposites containing L-CNC ( $1 \mathrm{wt} . \%)$. The highest biodegradation rates were observed in PLA/ATBC $/ \mathrm{CaCO}_{3}$ biocomposites. The induction period was 19 days shorter than for neat PLA films, and $94 \%$ biodegradation in 60 days was observed. In contrast, neat PLA exposed to the same conditions achieved only $16 \%$ biodegradation. Furthermore, the results of qualitative analyses (SEM, DSC, TGA and FTIR) of the biodegradation of PLA films in freshwater biotope showed that the biodegradation rate significantly increased with the addition of ATBC to the PLA matrix. Considerable changes in surface roughness, chemical composition and thermal properties were detected after three months of biodegradation. Moreover, the inhibiting effect of the lignin coating of CNC on the biodegradation of PLA ternary biocomposites was observed in the first months. Also in freshwater biotope, the highest biodegradation rate has been detected in PLA/ATBC $/ \mathrm{CaCO}_{3}$ biocomposites. Significant changes in chemical composition and thermal properties were observed even after one month of biodegradation.

This study found that the biodegradation potential of the PLA/ATBC $/ \mathrm{CaCO}_{3}$ biocomposites significantly increased due to the synergistic influence of both additives. In the chosen processing conditions, the ATBC plasticiser had a more profound effect on the enhancement of the crystallinity degree than both heterogeneous nucleation agents $\left(\mathrm{CaCO}_{3}\right.$ and L-CNC). Furthermore, the thermal stability of the ternary biocomposites based on $\mathrm{PLA} / \mathrm{ATBC} / \mathrm{CaCO}_{3}$ fell by $60^{\circ} \mathrm{C}$ and $27^{\circ} \mathrm{C}$ when compared to neat PLA and plasticised PLA/ATBC, respectively.

Author Contributions: Conceptualisation, P.B., M.B., L.B. and P.L.; methodology, P.B., M.B., L.B. and P.L.; validation, P.B., M.B. and L.B.; formal analysis, P.B. and M.B.; investigation, P.B., M.B. and L.B.; data curation, P.B., M.B. and L.B.; writing-original draft preparation, P.B. and M.B.; writing-review and editing, P.B., M.B., L.B. and P.L.; supervision, P.L.; project administration, P.B. and P.L.; funding acquisition, P.B., M.B., L.B. and P.L. All authors have read and agreed to the published version of the manuscript.

Funding: This research was funded by the [Ministry of Education, Youth and Sports of the Czech Republic and the European Union-European Structural and Investment Funds in the frames of Operational Program Research, Development and Education] - project Hybrid Materials for Hierarchical Structures [HyHi, Reg. No.CZ.02.1.01/0.0/0.0/16_019/0000843].

Institutional Review Board Statement: Not applicable.

Informed Consent Statement: Not applicable.

Data Availability Statement: The data presented in this study are available on request from the corresponding author. 
Conflicts of Interest: The authors declare no conflict of interest.

\section{References}

1. Thakur, V.K.; Thakur, M.K.; Kessler, M.R. Handbook of Composites from Renewable Materials, Structure and Chemistry; John Wiley \& Sons: Hoboken, NJ, USA, 2016; Volume 1, ISBN 1-119-22423-3.

2. Ebnesajjad, S. Handbook of Biopolymers and Biodegradable Plastics: Properties, Processing and Applications; William Andrew: Norwich, NY, USA, 2012; ISBN 1-4557-3003-3.

3. Maiza, M.; Benaniba, M.T.; Quintard, G.; Massardier-Nageotte, V. Biobased Additive Plasticizing Polylactic Acid (PLA). Polimeros 2015, 25, 581-590. [CrossRef]

4. Thompson, R.C.; Moore, C.J.; Vom Saal, F.S.; Swan, S.H. Plastics, the Environment and Human Health: Current Consensus and Future Trends. Philos. Trans. Royal Soc. B Biol. Sci. 2009, 364, 2153-2166. [CrossRef]

5. Kfoury, G.; Raquez, J.-M.; Hassouna, F.; Odent, J.; Toniazzo, V.; Ruch, D.; Dubois, P. Recent Advances in High Performance Poly (Lactide): From “Green” Plasticization to Super-Tough Materials via (Reactive) Compounding. Front. Chem. $2013,1,32$. [CrossRef] [PubMed]

6. Jacobsen, S.; Fritz, H.-G. Plasticizing Polylactide-the Effect of Different Plasticizers on the Mechanical Properties. Polym. Eng. Sci. 1999, 39, 1303-1310. [CrossRef]

7. Rahman, M.; Brazel, C.S. The Plasticizer Market: An Assessment of Traditional Plasticizers and Research Trends to Meet New Challenges. Prog. Polym. Sci. 2004, 29, 1223-1248. [CrossRef]

8. Vieira, M.G.A.; da Silva, M.A.; dos Santos, L.O.; Beppu, M.M. Natural-Based Plasticizers and Biopolymer Films: A Review. Eur. Polym. J. 2011, 47, 254-263. [CrossRef]

9. Xiao, H.; Liu, F.; Jiang, T.; Yeh, J.-T. Kinetics and Crystal Structure of Isothermal Crystallization of Poly (Lactic Acid) Plasticized with Triphenyl Phosphate. J. Appl. Polym. Sci. 2010, 117, 2980-2992. [CrossRef]

10. Burgos, N.; Martino, V.P.; Jiménez, A. Characterization and Ageing Study of Poly (Lactic Acid) Films Plasticized with Oligomeric Lactic Acid. Polym. Degrad. Stab. 2013, 98, 651-658. [CrossRef]

11. Liu, H.; Zhang, J. Research Progress in Toughening Modification of Poly (Lactic Acid). J. Polym. Sci. Part B Polym. Phys. 2011, 49, 1051-1083. [CrossRef]

12. Ljungberg, N.; Wesslen, B. Tributyl Citrate Oligomers as Plasticizers for Poly (Lactic Acid): Thermo-Mechanical Film Properties and Aging. Polymer 2003, 44, 7679-7688. [CrossRef]

13. Tan, B.H.; Muiruri, J.K.; Li, Z.; He, C. Recent Progress in Using Stereocomplexation for Enhancement of Thermal and Mechanical Property of Polylactide. ACS Sustain. Chem. Eng. 2016, 4, 5370-5391. [CrossRef]

14. Dartora, P.C.; da Rosa Loureiro, M.; de Camargo Forte, M.M. Crystallization Kinetics and Morphology of Poly (Lactic Acid) with Polysaccharide as Nucleating Agent. J. Therm. Anal. Calorim. 2018, 134, 1705-1713. [CrossRef]

15. Gupta, A.; Simmons, W.; Schueneman, G.T.; Mintz, E.A. Lignin-Coated Cellulose Nanocrystals as Promising Nucleating Agent for Poly (Lactic Acid). J. Therm. Anal. Calorim. 2016, 126, 1243-1251. [CrossRef]

16. Saeidlou, S.; Huneault, M.A.; Li, H.; Park, C.B. Poly (Lactic Acid) Crystallization. Prog. Polym. Sci. 2012, 37, 1657-1677. [CrossRef]

17. Samadi, K.; Francisco, M.; Hegde, S.; Diaz, C.A.; Trabold, T.A.; Dell, E.M.; Lewis, C.L. Mechanical, Rheological and Anaerobic Biodegradation Behavior of a Poly (Lactic Acid) Blend Containing a Poly (Lactic Acid)-Co-Poly (Glycolic Acid) Copolymer. Polym. Degrad. Stab. 2019, 170, 109018. [CrossRef]

18. Aitor, L.; Erlantz, L. A Review on the Thermomechanical Properties and Biodegradation Behaviour of Polyester. Eur. Polym. J. 2019, 121, 1-31.

19. Siparsky, G.L.; Voorhees, K.J.; Dorgan, J.R.; Schilling, K. Water Transport in Polylactic Acid (PLA), PLA/Polycaprolactone Copolymers, and PLA/Polyethylene Glycol Blends. J. Environ. Polym. Degrad. 1997, 5, 125-136.

20. Itävaara, M.; Karjomaa, S.; Selin, J.-F. Biodegradation of Polylactide in Aerobic and Anaerobic Thermophilic Conditions. Chemosphere 2002, 46, 879-885. [CrossRef]

21. Kolstad, J.J.; Vink, E.T.; De Wilde, B.; Debeer, L. Assessment of Anaerobic Degradation of Ingeo ${ }^{\mathrm{TM}}$ Polylactides under Accelerated Landfill Conditions. Polymer Degrad. Stab. 2012, 97, 1131-1141. [CrossRef]

22. Karlssion, S.; Ndazi, B.S. Characterization of Hydrolytic Degradation of Polylactic Acid/Rice Hulls Composites in Water at Different Temperatures. Express Polym. Lett. 2011, 5, 119-131.

23. Kale, G.; Kijchavengkul, T.; Auras, R.; Rubino, M.; Selke, S.E.; Singh, S.P. Compostability of Bioplastic Packaging Materials: An Overview. Macromol. Biosci. 2007, 7, 255-277. [CrossRef]

24. Cadar, O.; Paul, M.; Roman, C.; Miclean, M.; Majdik, C. Biodegradation Behaviour of Poly (Lactic Acid) and (Lactic Acid-Ethylene Glycol-Malonic or Succinic Acid) Copolymers under Controlled Composting Conditions in a Laboratory Test System. Polym. Degrad. Stab. 2012, 97, 354-357. [CrossRef]

25. Iovino, R.; Zullo, R.; Rao, M.A.; Cassar, L.; Gianfreda, L. Biodegradation of Poly (Lactic Acid)/Starch/Coir Biocomposites under Controlled Composting Conditions. Polym. Degrad. Stab. 2008, 93, 147-157. [CrossRef]

26. Soni, R.K.; Soam, S.; Dutt, K. Studies on Biodegradability of Copolymers of Lactic Acid, Terephthalic Acid and Ethylene Glycol. Polym. Degrad. Stab. 2009, 94, 432-437. [CrossRef]

27. Ren, Y.; Hu, J.; Yang, M.; Weng, Y. Biodegradation Behavior of Poly (Lactic Acid)(PLA), Poly (Butylene Adipate-CoTerephthalate)(PBAT), and Their Blends Under Digested Sludge Conditions. J. Polym. Environ. 2019, 27, 2784-2792. [CrossRef] 
28. Kallel, T.K.; Houichi, H.; Sayari, A.; Kammoun, M. Assessment of Biodegradation of PLA/PCL and PLA/PEG Biopolymers under Aerobic and Anaerobic Conditions. J. Mater. Environ. Sci. 2015, 6, 2542-2549.

29. Xu, H.; Yang, Y.; Yu, X. Lightweight Materials from Biopolymers and Biofibers; American Chemical Society: Washington, DC, USA, 2014; ISBN 0-8412-2997-X.

30. Tuomela, M.; Vikman, M.; Hatakka, A.; Itävaara, M. Biodegradation of Lignin in a Compost Environment: A Review. Bioresour. Technol. 2000, 72, 169-183. [CrossRef]

31. Micales, J.A.; Skog, K.E. The Decomposition of Forest Products in Landfills. Int. Biodeterior. Biodegrad. 1997, 39, 145-158. [CrossRef]

32. Hegde, S.; Dell, E.; Lewis, C.; Trabold, T.A.; Diaz, C.A. Anaerobic Biodegradation of Bioplastic Packaging Materials. In Proceedings of the 21st IAPRI World Conference on Packaging, Zhuhai, China, 19-22 June 2018.

33. Nekhamanurak, Y.B.; Patanathabutr, P.; Hongsriphan, N. Mechanical Properties of Hydrophilicity Modified CaCO3-Poly (Lactic Acid) Nanocomposite. Int. J. Appl. Phys. Math. 2012, 2, 98. [CrossRef]

34. Nekhamanurak, B.; Patanathabutr, P.; Hongsriphan, N. The Influence of Micro-/Nano-CaCO3 on Thermal Stability and Melt Rheology Behavior of Poly (Lactic Acid). Energy Procedia 2014, 56, 118-128. [CrossRef]

35. Sessini, V.; Palenzuela, M.; Damián, J.; Mosquera, M.E. Bio-Based Polyether from Limonene Oxide Catalytic ROP as Green Polymeric Plasticizer for PLA. Polymer 2020, 210, 123003. [CrossRef]

36. Lee, J.C.; Moon, J.H.; Jeong, J.-H.; Kim, M.Y.; Kim, B.M.; Choi, M.-C.; Kim, J.R.; Ha, C.-S. Biodegradability of Poly (Lactic Acid)(PLA)/Lactic Acid (LA) Blends Using Anaerobic Digester Sludge. Macromol. Res. 2016, 24, 741-747. [CrossRef]

37. Weng, Y.-X.; Wang, L.; Zhang, M.; Wang, X.-L.; Wang, Y.-Z. Biodegradation Behavior of P (3HB, 4HB)/PLA Blends in Real Soil Environments. Polym. Test. 2013, 32, 60-70. [CrossRef]

38. Amorin, N.S.; Rosa, G.; Alves, J.F.; Gonçalves, S.P.; Franchetti, S.M.; Fechine, G.J. Study of Thermodegradation and Thermostabilization of Poly (Lactide Acid) Using Subsequent Extrusion Cycles. J. Appl. Polym. Sci. 2014, 131, 1-8. [CrossRef]

39. Zaidi, L.; Kaci, M.; Bruzaud, S.; Bourmaud, A.; Grohens, Y. Effect of Natural Weather on the Structure and Properties of Polylactide/Cloisite 30B Nanocomposites. Polym. Degrad. Stab. 2010, 95, 1751-1758. [CrossRef]

40. Oliveira, M.; Santos, E.; Araújo, A.; Fechine, G.J.; Machado, A.V.; Botelho, G. The Role of Shear and Stabilizer on PLA Degradation. Polym. Test. 2016, 51, 109-116. [CrossRef]

41. Wu, H.; Nagarajan, S.; Zhou, L.; Duan, Y.; Zhang, J. Synthesis and Characterization of Cellulose Nanocrystal-Graft-Poly (d-Lactide) and Its Nanocomposite with Poly (1-Lactide). Polymer 2016, 103, 365-375. [CrossRef]

42. Sasaki, S.; Asakura, T. Helix Distortion and Crystal Structure of the $\alpha$-Form of Poly (1-Lactide). Macromolecules 2003, 36, 8385-8390. [CrossRef]

43. Androsch, R.; Schick, C.; Di Lorenzo, M.L. Melting of Conformationally Disordered Crystals (A'-Phase) of Poly (L-lactic Acid). Macromol. Chem. Phys. 2014, 215, 1134-1139. [CrossRef]

44. Borůvka, M.; Běhálek, L.; Novák, J. Properties and Crystallization of PLLA Biopolymers with Cellulose Nanocrystals and Organic Plasticizer. MM Sci. J. 2020, 2020, 4080-4085. [CrossRef]

45. Suksut, B.; Deeprasertkul, C. Effect of Nucleating Agents on Physical Properties of Poly (Lactic Acid) and Its Blend with Natural Rubber. J. Polym. Environ. 2011, 19, 288-296. [CrossRef]

46. Nelson, K.; Retsina, T.; Iakovlev, M.; van Heiningen, A.; Deng, Y.; Shatkin, J.A.; Mulyadi, A. American process: Production of low cost nanocellulose for renewable, advanced materials applications. In Materials Research for Manufacturing; Springer: Berlin/Heidelberg, Germany, 2016; pp. 267-302.

47. Boruvka, M.; Behalek, L.; Lenfeld, P.; Ngaowthong, C.; Pechociakova, M. Structure-Related Properties of Bionanocomposites Based on Poly (Lactic Acid), Cellulose Nanocrystals and Organic Impact Modifier. Mater. Technol. 2019, 34, 143-156. [CrossRef]

48. Lizundia, E.; Mateos, P.; Vilas, J.L. Tuneable Hydrolytic Degradation of Poly (l-Lactide) Scaffolds Triggered by ZnO Nanoparticles. Mater. Sci. Eng. C 2017, 75, 714-720. [CrossRef] [PubMed]

49. Albertsson, A.-C.; Varma, I.K. Aliphatic polyesters: Synthesis, properties and applications. In Degradable Aliphatic Polyesters; Springer: Berlin/Heidelberg, Germany, 2002; pp. 1-40. 